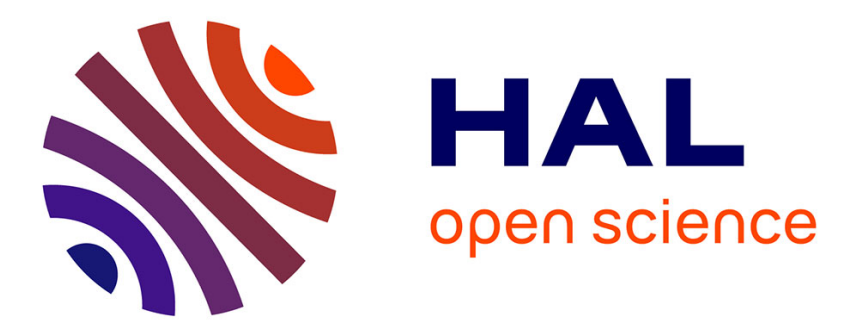

\title{
A tunable copper-catalyzed multicomponent reaction towards alkaloid-inspired indole/lactam polycycles
}

\author{
M. I D Mardjan, S. Périé, J-L Parrain, Laurent Commeiras
}

\section{To cite this version:}

M. I D Mardjan, S. Périé, J-L Parrain, Laurent Commeiras. A tunable copper-catalyzed multicomponent reaction towards alkaloid-inspired indole/lactam polycycles. Organic \& Biomolecular Chemistry, 2017, 15 (15), pp.3304 - 3309. 10.1039/c7ob00532f . hal-01907698

\section{HAL Id: hal-01907698 \\ https://hal.science/hal-01907698}

Submitted on 29 Oct 2018

HAL is a multi-disciplinary open access archive for the deposit and dissemination of scientific research documents, whether they are published or not. The documents may come from teaching and research institutions in France or abroad, or from public or private research centers.
L'archive ouverte pluridisciplinaire HAL, est destinée au dépôt et à la diffusion de documents scientifiques de niveau recherche, publiés ou non, émanant des établissements d'enseignement et de recherche français ou étrangers, des laboratoires publics ou privés. 


\title{
A tunable copper-catalyzed multicomponent reaction towards alkaloid-inspired indole/lactam polycycles $\uparrow$
}

\author{
M. I. D. Mardjan, S. Perie, J.-L. Parrain* and L. Commeiras (iD)*
}

A versatile copper(I)-catalyzed cascade multicomponent reaction strategy between readily available (Z)-3-iodoacrylic acids, terminal alkynes, and primary amines is reported, leading to a great diversity of complex heterocyclic backbones based on biorelevant indole/lactam scaffolds.

\section{Introduction}

Indole, which is one of the most important heterocyclic ring systems, is known to play an important role in several physiological and biochemical processes. ${ }^{1}$ For example tryptophan is an $\alpha$-amino acid that is used in the biosynthesis of proteins and it is also a precursor to neurotransmitters such as serotonin and melatonin. In addition, the indole nucleus is an inescapable structural component in many pharmaceutical agents displaying a broad spectrum of biological activities. Therefore, the interesting biological activities of such naturally or pharmaceutically occurring compounds bearing an indole moiety have captured the attention of the organic synthetic community and the discovery of new therapeutics is still of interest. As a matter of fact, the collection data of natural indole-inspired compounds for pharmaceutical tests suffer from the lack of general preparations addressing the substituent and scaffold diversity. Consequently, novel ways to prepare polycyclic indole scaffolds are thus very much desired and multicomponent reactions (MCRs) appear to be one of the most efficient tools and attractive strategies. ${ }^{2}$ Recently, we have developed a highly efficient copper-catalyzed multicomponent reaction (MCR) starting from readily available $(Z)$-3-iodoacrylic acids $\mathbf{1}$, terminal alkynes 2 , and primary amines 3 to smoothly access 5-hydroxy- $1 H^{-}$ pyrrol-2(5H)-ones 4 in good yields (Scheme 1 ). ${ }^{3}$

These latter are important five-membered heterocyclic compounds that not only can be found in several natural

Aix Marseille Univ, CNRS, Centrale Marseille, iSm2, Marseille, France. E-mail: laurent.commeiras@univ-amu.fr, jl.parrain@univ-amu.fr; Fax: (+33)-(0)491-288-86; Tel: (+33)-(0)491-289-126

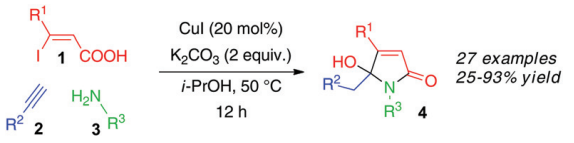

Scheme 1 Copper(I) mediated-MCR process for the synthesis of $\gamma$-hydroxybutyrolactams.

products, ${ }^{4}$ designed pharmaceutical molecules with significant biological properties ${ }^{5}$ but also as versatile building blocks in organic synthesis. ${ }^{6}$

Consequently, to address the modular preparation of indole alkaloids and having in mind that $\gamma$-hydroxybutyrolactams are both relevant scaffolds and excellent precursors of acyliminium derivatives, we planned to extend the copper-catalyzed MCR process for the preparation of substrates bearing an indole moiety $(5, \mathbf{6})$ and to build up, via a "one-pot" procedure including an intramolecular Pictet-Spengler reaction, a collection of diverse indole/lactam polycyclic derivatives such as fused tetrahydro- $\beta$-carboline-butyrolactam derivatives 7 and spiro-indolo-butyrolactams 8 (Scheme 2).

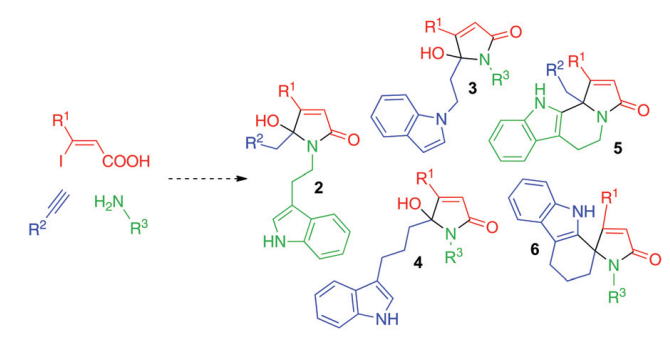

Scheme 2 Versatile MCR process. 


\section{Results and discussion}

\section{Synthesis of indolo- $\gamma$-hydroxybutyrolactams}

In the first instance, we turned our attention to the preparation of $\gamma$-hydroxybutyrolactams bearing an indole moiety. For this purpose, we explored several opportunities. The indole scaffold could be easily incorporated either on the primary amine or on the terminal alkyne. Our preliminary study ${ }^{3}$ has shown that starting from tryptamine 9, hydroxybutyrolactams $\mathbf{5 a}$ and $\mathbf{5 e}$ were obtained in very good yields ( 83 and $81 \%$ yield respectively).

Encouraged by these results, the scope and limitations of the copper-mediated MCR process were further exploited by using a diverse set of terminal alkynes 2 and $\beta$-substituted(Z)-3-iodoacrylic acids $\mathbf{1}$ (Scheme 3 ). In general, the reaction conditions are compatible with various functional groups associated with terminal alkynes, such as aromatic, protected alcohol as well as diethylacetal, and various 3-substituted iodoacrylic acids (methyl, phenyl, butyl or $\mathrm{CH}_{2} \mathrm{OMe}$ substituent) to smoothly furnish the desired $\gamma$-hydroxybutyrolactams 5 up to $85 \%$ yield.

The multicomponent reaction could also be conducted with readily available one-step synthesis of $N$-propargylindole 1, in which the indole scaffold is incorporated on the terminal alkyne (Scheme 4). First, we initiated our investigation with 1 equiv. of (Z)-3-iodobut-2-enoic acid 1a, 2 equiv. of
$\mathrm{N}$-propargyl-indole $\mathbf{1 0}$ and 2 equiv. of butyl amine $\mathbf{3 a}$, in the presence of $20 \mathrm{~mol} \%$ of copper iodide (CuI) and 2 equiv. of potassium carbonate, in isopropanol at $50{ }^{\circ} \mathrm{C}$. Under these standard conditions, the reaction was found to be incomplete with a conversion rate of $30 \%$. Satisfyingly, the conversion was complete by increasing the amount of both CuI ( 1 equiv.) and butylamine 3a (3 equiv.). In this case, indole 6a was obtained in $60 \%$ yield. Next, various $\beta$-substituted- $(Z)$-3-iodoacrylic acids $\mathbf{1}$ and primary amines $\mathbf{3}$ were tested to evaluate the generality of this strategy. To our delight, the desired hydroxylactams 6 were prepared in moderate to good yields (up to 64\% yield) whatever the nature of the nucleophilic primary amines (homoallyl-, butyl- and dimethoxyhomobenzyl amine) and whatever the nature of the $\beta$-substituent of the $\beta$-substituted(Z)-3-iodoacrylic acids $\mathbf{1}$ (methyl, phenyl or $\mathrm{CH}_{2} \mathrm{OMe}$ substituents).

All these results demonstrated the efficiency of this multibond-forming transformation in which $1 \mathrm{C}-\mathrm{O}, 1 \mathrm{C}-\mathrm{C}$ and $2 \mathrm{C}-\mathrm{N}$ bonds are created, starting from readily commercially available starting materials.

\section{Synthesis of fused tetrahydro- $\beta$-carboline-lactam derivatives} and indolo- $(5,6)$-spirolactams

Due to the presence of a carbonyl moiety on the nitrogen atom, $\mathrm{N}$-acyliminium ions (NAI) are highly reactive species towards nucleophiles. Hence, their electrophilic reactivity is

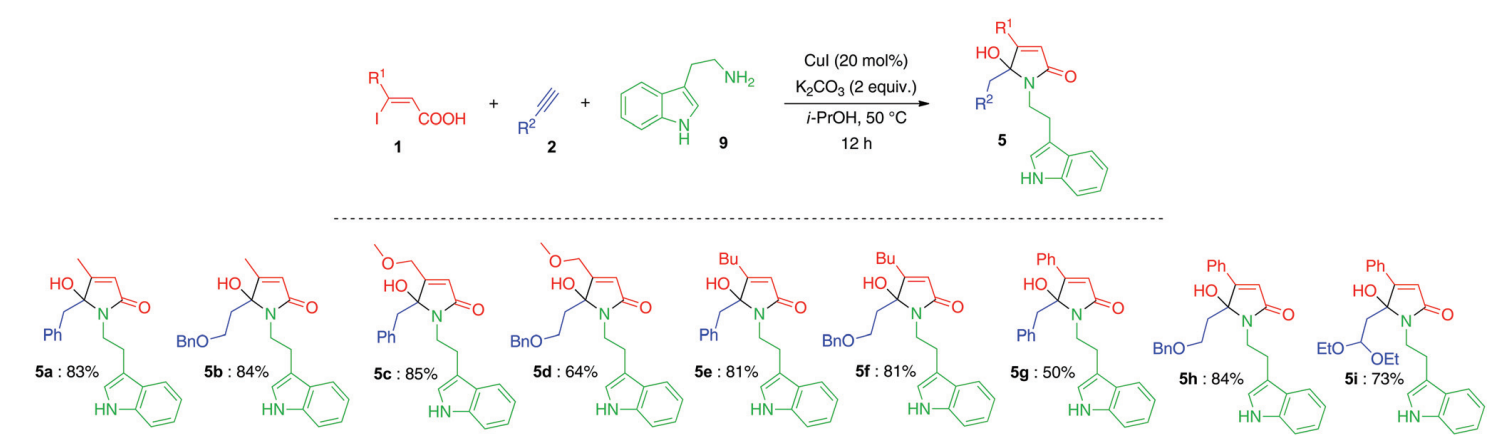

Scheme 3 Synthesis of 5-hydroxy-1H-pyrrol-2(5H)-ones 5 bearing an indole moiety.

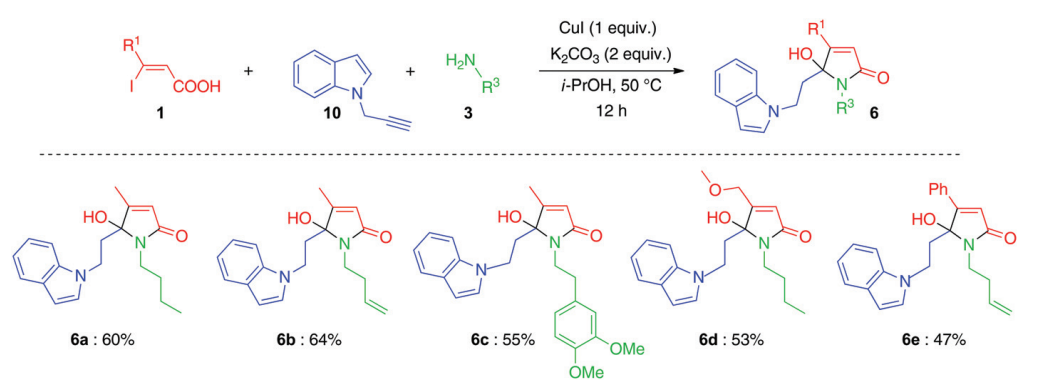

Scheme 4 Synthesis of 5-hydroxy-1H-pyrrol-2(5H)-ones 6 bearing an indole moiety. 
extensively used for the creation of carbon-carbon or carbonheteroatom bonds in both inter- or intra-molecular fashions with respect to the synthesis of alkaloid products. Given the high nucleophilic character of indole, this latter was proven to be a good candidate in the $N$-acyliminium ion process or Pictet-Spengler reaction.

By taking advantage of this reactivity, our next purpose was to investigate the reactivity of 5-hydroxy- $1 H$-pyrrol-2( $5 H$ )-ones 4 as an equivalent of the $\mathrm{N}$-acyliminium ion for the direct synthesis of polyheterocyclic compounds through an intramolecular C-2 Friedel-Crafts alkylation. Indeed, considering the structure of $\gamma$-hydroxybutyrolactams, the nucleophiles can be installed either in the amine site or alkyne part. While the former may allow us to afford the fused tetrahydro$\beta$-carboline-lactam derivatives 7 (Scheme 5a), the latter may lead to the formation of (5,5)-spirolactams 8 (Scheme 5b). Our objective was to incorporate the NAI reactions into the cascade sequence, including enyne coupling/heterocyclisation/ $\gamma$-hydroxylactam formation/NAI formation/intramolecular Friedel-Crafts alkylation.

Before attempting the "one-pot" cascade towards the desired fused tetrahydro- $\beta$-carboline-lactam derivatives 7 , we first validated the transformation from $5 \mathbf{a}$ to $7 \mathbf{a}$ in the presence of hydrochloric acid solution $(6 \mathrm{M})$ at $50{ }^{\circ} \mathrm{C}$ (Scheme 6). Satisfyingly, the cyclisation smoothly occurred in $2 \mathrm{~h}$ furnishing the expected product $7 \mathbf{a}$ in $79 \%$ yield.

The structure of $7 \mathbf{a}$ was unambiguously confirmed by $\mathrm{X}$-ray crystallographic analysis proving that the intramolecular Friedel-Craft alkylation occurred with a C-2 regioselectivity. ${ }^{8}$

Having proved that $\gamma$-hydroxybutyrolactam $\mathbf{5 a}$ can be transformed into fused-tetrahydro- $\beta$-carboline-lactam $7 \mathbf{a}$, we decided to investigate the "one-pot" cascade (Scheme 7). (Z)- $\beta$-Iodo- $\alpha, \beta$-unsaturated acids $\mathbf{1}$, phenyl acetylene and trypt-

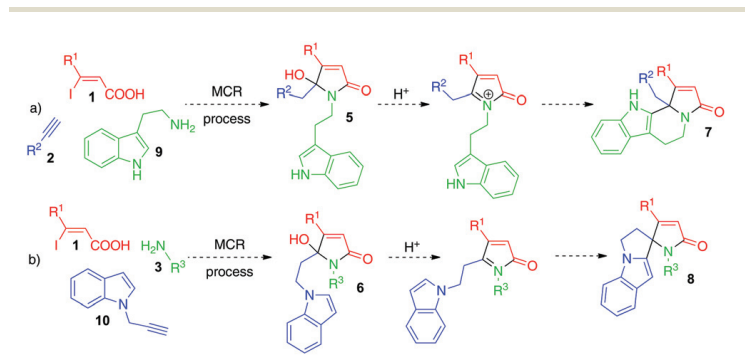

Scheme 5 Multi-bond-forming transformation for a straightforward synthesis of 7 and 8 .

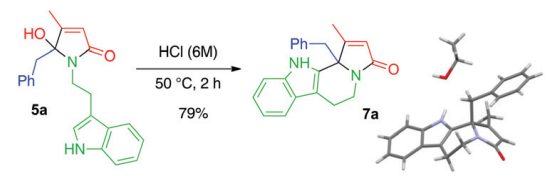

Scheme 6 Transformation of $5 a$ to $7 a$. amine 9 were subjected to the copper-catalyzed-multicomponent reaction. After performing the reaction overnight, hydrochloric acid solution (6 M) was added to the mixture and the reaction was continued until the total consumption of hydroxylactam $(4 \mathrm{~h})$. Pleasingly, the "one-pot" cascade process was efficient affording the desired fused tetrahydro$\beta$-carboline-lactam derivative 7 a in $82 \%$ yield. Subsequently, this procedure was found to be general and a diverse set of substituents $\left(\mathrm{R}^{1}\right.$ and $\mathrm{R}^{2}=$ alkyl, aromatic or protected alkoxy or aldehyde groups) were properly installed in such reaction. It is worth noting that starting from 3,3-diethoxyprop-1-yne as a terminal alkyne led us to obtain the corresponding aldehyde $7 \mathrm{c}$ in $36 \%$ yield. However, most of the polyheterocyclic compounds 7 were prepared in moderate yield (32-52\%). In an attempt to increase the yield of the desired product, the same "one-pot" sequence was performed by using a more diluted aqueous solution of $\mathrm{HCl}(1 \mathrm{M})$. Under this condition, indoles 7 were obtained in better yield, ranging from 53 to $86 \%$, demonstrating the power of this strategy.

Installing the nucleophilic site (indole moiety) on the primary amine partners allowed us to access heterocyclic compounds with tetrahydro- $\beta$-carboline scaffold, starting from terminal alkynes bearing such nucleophile sites, and is a new synthetic route to access spirolactams derivatives 8. Our initial efforts towards this goal focused on the reaction cascade with $N$-propargyl-indole $\mathbf{1 0}$ in order to prepare the corresponding $(5,5)$-spirolactam moiety. Unfortunately, by treating hydroxylactam 6a with a hydrochloric acid solution (6 M) or with 1,1'-binaphthyl-2,2'-diylhydrogenphosphate or by applying the MCR process, the Friedel-Crafts alkylation did not occur. Instead, a dehydration reaction took place to furnish the corresponding alkylidenebutyrolactam. A way to circumvent this non-desired reactivity was to perform the reaction cascade with 3-(but-3yn-1-yl)-1H-indoles 11. Alkynes $\mathbf{1 1}$ were prepared in a two-step synthesis from indole through a sequence involving Michael addition $^{9}$ (with acrolein) and Bestmann-Ohira homologation. ${ }^{10}$ As an attempt to prove our concept, we initially prepared $\gamma$-hydroxybutyrolactam 12a from 11a. Since this terminal alkyne contains a non-activated terminal alkyne function, the reaction was carried out in the presence of 4 equiv. of primary amine at $45{ }^{\circ} \mathrm{C}$ (the previously reported optimal conditions). ${ }^{3}$ The desired $\gamma$-hydroxybutyrolactam 12a was obtained in moderate yield (43\%), together with the side product of pyran-2-one 13a (via a 6-endo cyclisation of enynoic acid intermediate, ratio $12: 13 a=1: 0.22$ ). Finally, the treatment of 12a with a hydrochloric acid solution (6 M) gave the desired (5,6)-spirolactam 14a in $79 \%$ yield (Scheme 8). The structure of the spirolactam 14a was unambiguously confirmed by X-ray crystallographic analysis confirming that the intramolecular Friedel-Craft alkylation occurred with a complete $\mathrm{C}-2$ regioselectivity. ${ }^{11}$ Having proved the concept of the synthesis of $(5,6)$-spirolactam, the MCR process, starting from 3-(but-3-yn-1-yl)- $1 H$-indole 11a, (Z)-3-iodobut-2-enoic acid 1a and butyl amine 3a, was then investigated. 


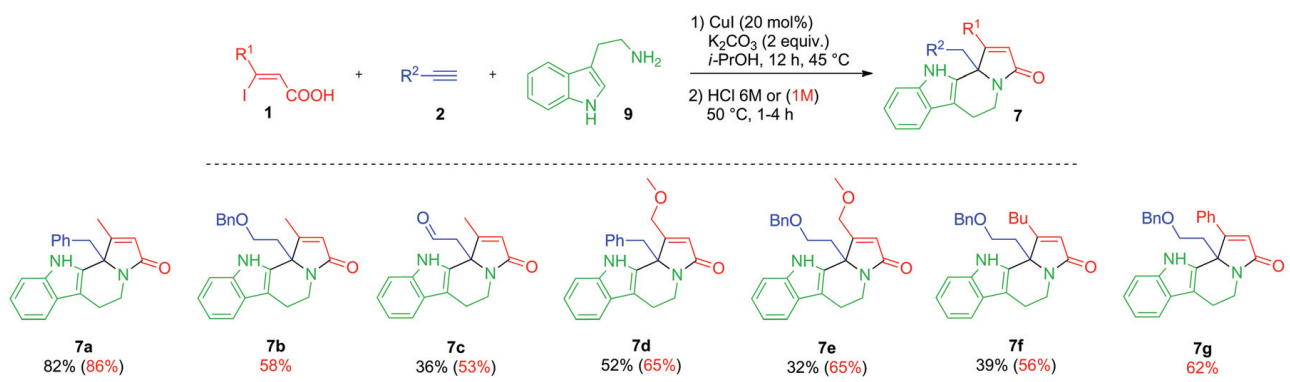

Scheme 7 Synthesis of fused tetrahydro- $\beta$-carboline-lactam derivatives 7.

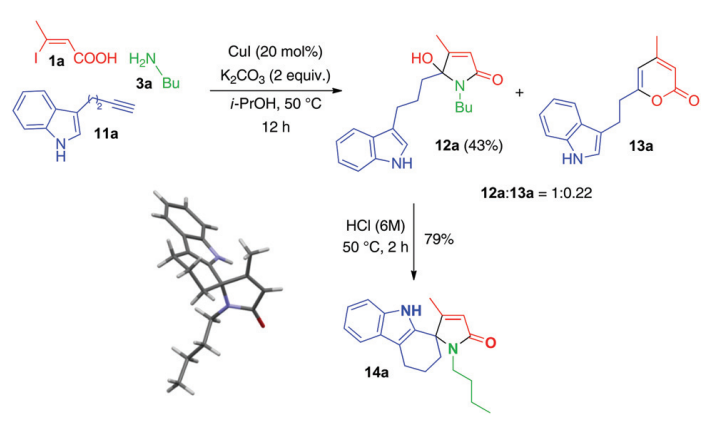

Scheme 8 Proof of concept of the preparation of $(5,6)$-spirolactam $14 a$.

Pleasingly, the corresponding (5,6)-spirolactam 14a was obtained in $43 \%$ isolated yield (Scheme 9). This moderate yield could be explained by the formation of pyran-2-one 13a $(20 \%)$ that was found to be inert under the reaction conditions. Although 14a was obtained in $43 \%$ yield (which in fact corresponds to an $81 \%$ average yield per step), the "one-pot" cascade provides a useful method for building $(5,6)$-spirolactam scaffolds from readily available compounds, which encouraged us to carry out further explorations. Therefore, several (Z)- $\beta$-iodo- $\alpha, \beta$-unsaturated acids 1 , primary amines 3 , as well as indole derivatives $\mathbf{1 1}$ were tested (Scheme 9). As a general trend, the isolated yields of the $(5,6)$-spirolactams $\mathbf{8 a}-\mathbf{8 e}$ were found to be relatively moderate $(30-40 \%)$ due to, equally, the formation of the 6-membered lactones 12 (around $20 \%$ ). However, these isolated yields can be considered as satisfactory regarding the number of steps of this MCR cascade including as well the construction of a quaternary center. It is worth noting that the relative amount of $\mathbf{1 2}$ was found to be dependent on the nature of the substituent on the acid partner 1 .

The more electron withdrawing group the substituent was, the higher relative amount of lactone $\mathbf{1 2}$ would be. Indeed, starting from $\mathrm{CH}_{2} \mathrm{OMe}$ or phenyl $\beta$-substituted-(Z)-3-iodoacrylic acids $\mathbf{1}$, the amount of the 6-membered lactones $12 \mathrm{f}$ and $\mathbf{1 2} \mathrm{g}$ is 35 and $68 \%$ respectively. $^{12}$

\section{Conclusions}

In summary, we have described straightforward and versatile copper-catalyzed multi-bond-forming transformations for the construction of pharmaceutically interesting complex polyheterocyclic scaffolds containing an indole moiety. These processes feature readily available starting materials, mild reaction conditions, and tolerance of a wide range of functional groups. The generation of molecular complexity in a "one-pot" process should make this method a useful organic synthetic tool.

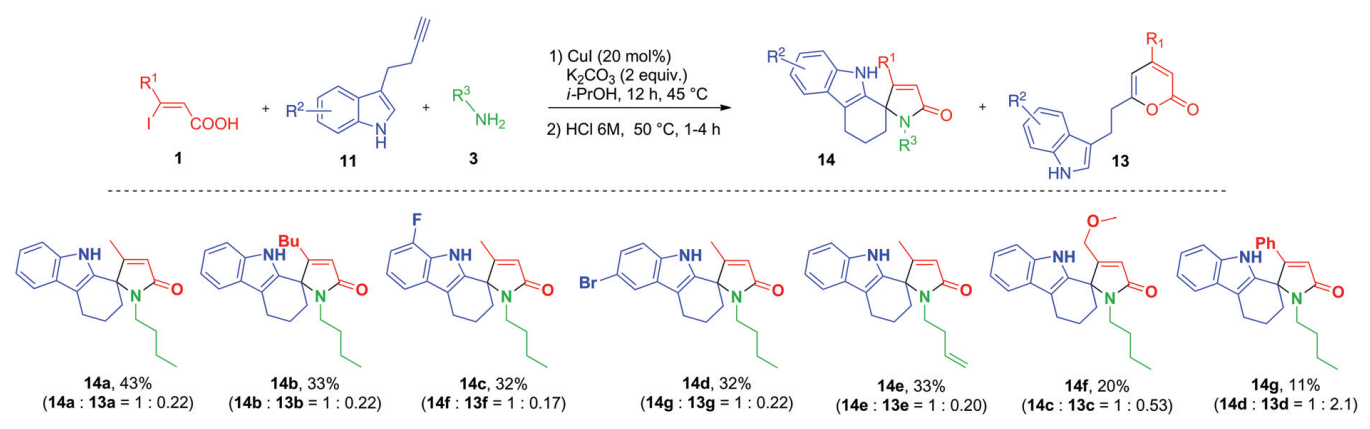

Scheme 9 Synthesis of $(5,6)$-spirolactams 8 


\section{Experimental section}

\section{General procedure for the synthesis of 5}

(Z)-3-Substituted-3-iodoprop-2-enoic acid derivative 1 (2.0 mmol, 1 equiv.) was dissolved in i-PrOH $(7 \mathrm{~mL})$ in an oven-driedSchlenk tube. $\mathrm{K}_{2} \mathrm{CO}_{3}$ (553 mg, $4.0 \mathrm{mmol}, 2$ equiv.) was then added to the solution and the suspension was stirred for $10 \mathrm{~min}$ under argon. The mixture was then degassed at $-78^{\circ} \mathrm{C}$ for $2 \times 10 \mathrm{~min}$ and the vessel was backfilled with argon. After warming to room temperature, terminal alkyne $2(4.0 \mathrm{mmol}$, 2 equiv.), tryptamine 9 ( $641 \mathrm{mg}, 4.0 \mathrm{mmol}, 2$ equiv.) and CuI (76 mg, $0.4 \mathrm{mmol}, 0.2$ equiv.) were respectively added into the mixture. The mixture was then rapidly degassed and the vessel was backfilled with argon. The sealed Schlenk tube was placed in the preheated oil bath $\left(50^{\circ} \mathrm{C}\right)$ and was stirred overnight. The reaction mixture was cooled to $0{ }^{\circ} \mathrm{C}$, then quenched by the addition of an aqueous saturated $\mathrm{NH}_{4} \mathrm{Cl}$ solution and stirred for further $15 \mathrm{~min}$. The mixture was filtered through a pad of Celite ${ }^{\circledR}$. The aqueous phase was extracted with ethyl acetate and the combined organic layers were washed with brine, dried over $\mathrm{Na}_{2} \mathrm{SO}_{4}$ and concentrated under reduced pressure. The crude product was then purified by flash chromatography on silica gel using petroleum ether : ethyl acetate as the eluent.

\section{General procedure for the synthesis of 6}

(Z)-3-Substituted-3-iodoprop-2-enoic acid derivative $\mathbf{1}$ (1.0 mmol, 1 equiv.) was dissolved in i-PrOH $(3.5 \mathrm{~mL})$ in an oven-dried-Schlenk tube. $\mathrm{K}_{2} \mathrm{CO}_{3}$ ( $277 \mathrm{mg}, 2.0 \mathrm{mmol}, 2$ equiv.) was then added to the solution and the suspension was stirred for 10 min under argon. The mixture was then degassed at $-78{ }^{\circ} \mathrm{C}$ for $2 \times 10 \mathrm{~min}$ and the vessel was backfilled with argon. After warming to room temperature, 1-prop-2-yn-1-yl$1 H$-indole 10 (310 mg, $2.0 \mathrm{mmol}, 2$ equiv.), primary amine 3 (3.0 mmol, 3 equiv.) and $\mathrm{CuI}$ (190 mg, $1.0 \mathrm{mmol}, 1$ equiv.) were respectively added into the mixture. The mixture was then rapidly degassed and the vessel was backfilled with argon. The sealed Schlenk tube was placed in the preheated oil bath $\left(50{ }^{\circ} \mathrm{C}\right)$ and was stirred overnight. The reaction mixture was cooled to $0{ }^{\circ} \mathrm{C}$, then quenched by the addition of an aqueous saturated $\mathrm{NH}_{4} \mathrm{Cl}$ solution and stirred for further $15 \mathrm{~min}$. The mixture was filtered through a pad of Celite ${ }^{\circledR}$. The aqueous phase was extracted with ethyl acetate and the combined organic layers were washed with brine, dried over $\mathrm{Na}_{2} \mathrm{SO}_{4}$ and concentrated under reduced pressure. The crude product was then purified by flash chromatography on silica gel using petroleum ether : ethyl acetate as the eluent.

\section{General procedure for the synthesis of 7}

(Z)-3-Substituted-3-iodoprop-2-enoic acid derivative 1 (1.0 mmol, 1 equiv.) was dissolved in i-PrOH $(3.5 \mathrm{~mL})$ in an oven-driedSchlenk tube. $\mathrm{K}_{2} \mathrm{CO}_{3}(277 \mathrm{mg}, 2.0 \mathrm{mmol}, 2$ equiv.) was then added to the solution and the suspension was stirred for 10 min under argon. The mixture was then degassed at $-78{ }^{\circ} \mathrm{C}$ for $2 \times 10 \mathrm{~min}$ and the vessel was backfilled with argon. After warming to room temperature, terminal alkyne $2(2.0 \mathrm{mmol}$, 2 equiv.), tryptamine 9 (320 mg, $2.0 \mathrm{mmol}, 2$ equiv.) and CuI
( $38 \mathrm{mg}, 0.2 \mathrm{mmol}, 0.2$ equiv.) were respectively added into the mixture. The mixture was then rapidly degassed and the vessel was backfilled with argon. The sealed Schlenk tube was placed in the preheated oil bath $\left(50{ }^{\circ} \mathrm{C}\right)$ and was stirred overnight. The reaction mixture was cooled to $0{ }^{\circ} \mathrm{C}$, and then a solution of hydrochloric acid (3.4 mL, $6 \mathrm{M}, 20$ equiv.) was added dropwise. The reaction was then heated at $50{ }^{\circ} \mathrm{C}$ until the disappearance of the $\gamma$-hydroxybutyrolactam checked by TLC. The reaction mixture was cooled to $0^{\circ} \mathrm{C}$ and then filtered through a pad of Celite ${ }^{\circledR}$. The aqueous phase was extracted with ethyl acetate and the combined organic layers were washed with brine, dried over $\mathrm{Na}_{2} \mathrm{SO}_{4}$ and concentrated under reduced pressure. The crude product was then purified by flash chromatography on silica gel using petroleum ether : ethyl acetate as the eluent.

Or (Z)-3-Substituted-3-iodoprop-2-enoic acid derivative 1 (0.5 mmol, 1 equiv.) was dissolved in i-PrOH $(1.75 \mathrm{~mL})$ in an oven-dried-Schlenk tube. $\mathrm{K}_{2} \mathrm{CO}_{3}(138 \mathrm{mg}, 1.0 \mathrm{mmol}, 2$ equiv.) was then added to the solution and the suspension was stirred for $10 \mathrm{~min}$ under argon. The mixture was then degassed at $-78{ }^{\circ} \mathrm{C}$ for $2 \times 10 \mathrm{~min}$ and the vessel was backfilled with argon. After warming to room temperature, terminal alkyne 2 (1.0 mmol, 2 equiv.), tryptamine 9 (160 mg, $1.0 \mathrm{mmol}$, 2 equiv.) and $\mathrm{CuI}$ (19 $\mathrm{mg}, 0.1 \mathrm{mmol}, 0.2$ equiv.) were respectively added into the mixture. The mixture was then rapidly degassed and the vessel was backfilled with argon. The sealed Schlenk tube was placed in the preheated oil bath $\left(50{ }^{\circ} \mathrm{C}\right)$ and was stirred overnight. The reaction mixture was cooled to $0{ }^{\circ} \mathrm{C}$, and then a solution of hydrochloric acid (3.5 mL, $1 \mathrm{M}, 7$ equiv.) was added dropwise. The reaction was then heated at $50{ }^{\circ} \mathrm{C}$ until the disappearance of the $\gamma$-hydroxybutyrolactam checked by TLC. The reaction mixture was cooled to $0{ }^{\circ} \mathrm{C}$ and then filtered through a pad of Celite ${ }^{\circledR}$. The aqueous phase was extracted with ethyl acetate and the combined organic layers were washed with brine, dried over $\mathrm{Na}_{2} \mathrm{SO}_{4}$ and concentrated under reduced pressure. The crude product was then purified by flash chromatography on silica gel using petroleum ether : ethyl acetate (stated below) as the eluent.

\section{General procedure for the synthesis of 14}

(Z)-3-Substituted-3-iodoprop-2-enoic acid derivative $\mathbf{1}$ ( $0.5 \mathrm{mmol}, 1$ equiv.) was dissolved in i-PrOH $(1.75 \mathrm{~mL})$ in an oven-dried-Schlenk tube. $\mathrm{K}_{2} \mathrm{CO}_{3}(139 \mathrm{mg}, 1.0 \mathrm{mmol}, 2$ equiv.) was then added to the solution and the suspension was stirred for $10 \mathrm{~min}$ under argon. The mixture was then degassed at $-78{ }^{\circ} \mathrm{C}$ for $2 \times 10 \mathrm{~min}$ and the vessel was backfilled with argon. After warming to room temperature, terminal alkyne 2 (1.0 mmol, 2 equiv.), primary amine 3 (2.0 mmol, 4 equiv.) and CuI (19 mg, $0.1 \mathrm{mmol}, 0.2$ equiv.) were respectively added into the mixture. The mixture was then rapidly degassed and the vessel was backfilled with argon. The sealed Schlenk tube was placed in the preheated oil bath $\left(45^{\circ} \mathrm{C}\right)$ and was stirred overnight. The reaction mixture was cooled to $0{ }^{\circ} \mathrm{C}$, and then $1.7 \mathrm{~mL}$ of a solution of hydrochloric acid ( $6 \mathrm{M}, 20$ equiv.) was added dropwise. The reaction was then heated at $50{ }^{\circ} \mathrm{C}$ until the disappearance of the $\gamma$-hydroxybutyrolactam checked by 
TLC. The reaction mixture was cooled to $0{ }^{\circ} \mathrm{C}$ and then filtered through a pad of Celite®. The aqueous phase was extracted with ethyl acetate and the combined organic layers were washed with brine, dried over $\mathrm{Na}_{2} \mathrm{SO}_{4}$ and concentrated under reduced pressure. The crude product was then purified by flash chromatography on silica gel using petroleum ether: ethyl acetate as the eluent.

\section{Acknowledgements}

The Ministry of Research, Technology and Higher Education (Republic of Indonesia), the CNRS and Aix Marseille Université (UMR 7313) are gratefully acknowledged for financial support.

\section{Notes and references}

1 (a) N. K. Kaushik, N. Kaushik, P. Attri, N. Kumar, C. H. Kim, A. K. Verma and E. H. Choi, Molecules, 2006, 18, 6620; (b) T. V. Sravanthi and S. L. Manju, Eur. J. Pharm. Sci., 2016, 91, 1.

2 (a) Multicomponent Reactions, ed. J. Zhu and H. Bienaymé, Wiley-VCH, Weinheim, 2005; (b) B. B. Touré and D. G. Hall, Chem. Rev., 2009, 109, 4439; (c) B. Jiang, T. Rajale, W. Wever, S.-J. Tu and G. Li, Chem. - Asian J., 2010, 5, 2318-2335; (d) E. Ruijter, R. Scheffelaar and R. V. A. Orru, Angew. Chem., Int. Ed., 2011, 50, 6234; (e) M. J. Climent, A. Corma and S. Iborra, RSC Adv., 2012, 2, 16; (f) A. Dömling, W. Wang and K. Wang, Chem. Rev., 2012, 112, 3083; $(g)$ S. Brauch, S. S. van Berkel and B. Westermann, Chem. Soc. Rev., 2013, 42, 4948.
3 M. I. D. Mardjan, J.-L. Parrain and L. Commeiras, Adv Synth. Catal., 2016, 358, 543.

4 For a recent review, see: B. Nay, N. Riache and L. Evanno, Nat. Prod. Rep., 2009, 26, 1044.

5 For recent examples of indole compounds with significant biological activity, see: (a) U. A. Pereira, L. C. A. Barbosa, C. R. A. Maltha, A. J. Demuner, M. A. Masood and A. L. Pimenta, Eur. J. Med. Chem., 2014, 82, 127; (b) O. S. Kanishchev, A. Lavoignat, S. Picot, M. Medebielle and J.-P. Bouillon, Bioorg. Med. Chem. Lett., 2013, 23, 6167; (c) D. Cornut, H. Lemoine, O. Kanishchev, E. Okada, F. Albrieux, A. H. Beavogui, A.-L. Bienvenu, S. Picot, J.-P. Bouillon and M. Medebielle, J. Med. Chem., 2013, 56, 73.

6 (a) F. Zhang, N. S. Simpkins and A. J. Blake, Org. Biomol. Chem., 2009, 7, 1963; (b) F. E. Chen, H. F. Dai, Y. Y. Kuang and H. Q. Jia, Tetrahedron: Asymmetry, 2003, 14, 3667; (c) F. Pin, S. Comesse, B. Garrigues, S. Marchalin and A. Daïch, J. Org. Chem., 2007, 72, 1181; (d) B. B. Snider and B. J. Neubert, J. Org. Chem., 2004, 69, 8952.

7 N. Haider, T. Kabicher, J. Käferböck and A. Plenk, Molecules, 2007, 12, 1900.

8 CCDC 1524381 contains the supplementary crystallographic data for this paper.

9 S.-K. Xiang, B. Zhang, L.-H. Zhang, Y. Cui and N. Jiao, Chem. Commun., 2011, 47, 8097.

10 S. Müller, B. Liepold, G. J. Roth and H. J. Bestmann, Synlett, 1996, 6, 521.

11 CCDC 1524380 contains the supplementary crystallographic data for this paper.

12 The ratio of $\mathbf{1 3}$ and $\mathbf{1 4}$ was calculated from the crude ${ }^{1} \mathrm{H}$ NMR spectrum. 